\title{
Does the informational role of the Annual General Meeting depend on a country's legal tradition?
}

\author{
Monica Martinez-Blasco, IQS School of Management-Universitat Ramon Llull* \\ Josep Garcia-Blandon, IQS School of Management-Universitat Ramon Llull** \\ Josep Maria Argiles-Bosch, Universitat de Barcelona***
}

* Associate Professor of Finance. IQS School of Management-Universitat Ramon Llull.

** Full Professor of Finance. IQS School of Management-Universitat Ramon Llull.

***Associate Professor of Accounting. Department of Accounting-Universitat de Barcelona.

Corresponding author:

Monica Martinez-Blasco

IQS School of Management-Universitat Ramon Llull

Via Augusta 390

08017 Barcelona, Spain

monica.martinez@iqs.edu

Tel +34.932.672.126

Fax +34.932 .672 .032$ 
Does the informational role of the Annual General Meeting depend on a country's legal tradition?

\begin{abstract}
:
The annual general meeting (AGM) constitutes the most important corporate event. Nevertheless, its role as an efficient instrument for corporate governance has recently come under increasing scrutiny, and numerous proposals for reform have emerged as a result. The purpose of this paper is to assess the release of valuerelevant information during the AGM by analysing its impact on returns, returns volatility, and trading volumes in a sample of common- and civil-law countries. In one of the most influential articles in the field of corporate governance, La Porta et al. (1998) examine the relationship between legal systems and shareholder protection. Given the importance of a country's legal tradition regarding not only shareholders' rights but also the role they play in the company, we cannot assume on a prior basis that results obtained in countries in which the legal tradition is based on the common law, like the U.S. and the U.K., can be directly extrapolated to countries with different legal traditions. Our results emphasise the role of national idiosyncratic characteristics among the civil-law countries analysed and show a very close relationship to the AGM in common-law countries.
\end{abstract}

Keywords: Annual general meeting; Informational content; Civil-law countries; Common-law countries

JEL Codes: G14; G15; G34 


\section{Introduction}

In this paper, we focus our attention on a main mechanism that, at least in theory, should guarantee good corporate governance: the annual general meeting (AGM). During the AGM, corporate executives address both shareholders and the financial markets. From a legal standpoint, the AGM constitutes a main corporate governance instrument that enables shareholders to limit the possibility of expropriation by managers. Certain decisions can only be approved at the AGM, for example, the election of the board of directors, and important managerial announcements, usually concerning managers' views about the company's prospects, are often made there. Stratling (2003) defines the following main functions of the AGM: (1) to inform shareholders about the company's financial results and major business decisions that have been made; (2) to obtain shareholders' approval of the decisions that do not rely on the managerial discretion of the board; and (3) to provide a forum for discussion between managers and shareholders on the past performance of the company and its future actions and prospects. Two of these functions involve the transmission of relevant information from managers to shareholders. Even more precisely, Olibe (2002), analysing U.K.-based firms listed in the U.S. market, points out three important reasons that the AGM is likely to provide information to the market: First, investors' participation suggests to that these annual meetings provide information beyond preliminary earnings announcements and annual reports and accounts. Second, if the U.K. company law mandates the AGM, it is because data not available in previous financial reports are released during the AGM. Third, managers often provide more qualitative and forward-looking information during the AGM.

There are four lines of research that address the AGM (Catasús 2007, p. 169): (1) studies that examine the informational content of the AGM; (2) the relation of the AGM to corporate governance issues, like voting practices and participation at the event; (3) critical historical analysis of specific events that occurred at an AGM; and (4) sociological theories to consider the meetings between investors and managers. While conclusions regarding the second line of research tend to find the AGM to be an ineffective monitoring management tool for minority shareholders, and therefore dispensable (Stratling 2003), we cannot propose to abolish these meetings based only on this approach. There is, at least one value-relevant function of the AGM that deserves to be analysed in depth: the informational content of the AGM and the international differences across countries. Our research analyses the AGM and its informational content in countries with different legal traditions, extending the existing literature that follows the first line of research.

We found only a few articles addressing the information contents of the AGM; with only one exception, all focused on companies listed in common-law stock markets. Firth (1981) conducted research with a sample of 120 companies listed on the U.K. stock market using weekly data. He fails to report abnormal stock price or trading volume behaviour around AGM dates, therefore concluding that these meetings do not seem to provide higher levels of information. Nevertheless, since he uses weekly data, he cannot properly determine the response of the market, which normally lasts for some days, and it is also difficult to compare his results with subsequent research. Some years later, Brickley (1985) carried out his research with a random sample of 100 firms listed with the Center for Research in Security Prices for the period 1978-82 to analyse stock return behaviour around the event. Using daily data, he finds positive and statistically significant abnormal returns around shareholder meetings, suggesting that AGMs often contain important managerial announcements. Brickley explains this result based on the risk and return trade-off around predictable events developed by Kalay and Loewestein (1985).

Ten years later, Rippington and Taffler (1995) tested the information content of four types of corporaterelevant events, one of them being the AGM. The sample includes 337 U.K. companies listed on the London Stock Exchange. They find only a small price reaction to AGMs, thus concluding that AGMs seem to convey little relevant information to the market.

Finally, Olibe (2002) addresses the effects of AGMs on absolute and squared returns, as well as trading values, with a sample of 227 firms registered in the U.K. whose shares are traded on the New York Stock Exchange (NYSE) and the American Stock Exchange (AMEX). His results show significant price changes for both absolute and squared returns, as well as abnormal trading volumes. Nevertheless, he only performs the parametric $t$-test, and the significance of trading volumes is not robust in terms of the way volumes are defined. He also warns about the lack of generalisation of his results to other stock markets.

Summarising the above-listed studies, Rippington and Taffler (1995), analysing the change in returns, and Olibe (2002), focusing on the change in volatility, find a weak reaction of stock prices to AGMs in the U.K., while Brickley (1985) shows evidence of abnormal returns around AGMs in the U.S. (he does not take into account trading volumes or volatility). Firth (1981) reports no evidence of abnormal returns using weekly data. Regarding trading volumes, only Firth (1981) and Olibe (2002) address the issue, with contradictory results. As can be seen, the studies developed in common-law countries have followed different approaches to assess the informational content of the event.

On the other hand, the first investigation of the issue in a civil-law country is found in the work of 
Garcia-Blandon et al. (2011, 2012), who use daily data and two different methodologies to assess the informational content of the AGM in Spain. Both methodologies show that AGMs have no significant effects on returns, volatility, or trading volumes, indicating that no relevant information is released to the financial market during these meetings.

To assess the informational content of the AGM in common- and civil-law countries, we empirically test whether there are differences in the AGM's impact on returns, returns volatility, and trading volumes in a sample of common- and civil-law countries. Abnormal price changes (Beaver 1968) and trading volumes (Kim and Verrecchia 1991) are investors' responses to disclosure information; thus, we expect abnormal price changes and trading volumes whenever the AGM translates new information to the financial markets. We have found that common-law countries share a quite similar level of information disclosure during the AGM, while national idiosyncratic characteristics among the civil-law countries would explains its despair reactions.

This paper contributes to the extant research in international corporate governance in two different ways: First, we update and contrast the results found in Brickley (1985), Rippington and Taffler (1995), and Olibe (2002) for companies belonging to the Dow Jones Industrial Average (DJIA) and the Financial Times Stock Exchange (FTSE) All-Share Index. We have investigated the behaviour of returns, returns volatility, and trading volumes for both samples around AGM dates. Second, we address the release of value-relevant information during AGMs for the first time in France, Germany, and Japan, all of which are civil-law countries. Since La Porta et al. (1998) pointed out the importance of a country's legal tradition on corporate governance issues, we cannot assume on a prior basis that results obtained in countries whose legal tradition is based on the common law, like the U.K. and the U.S., can be directly extrapolated to other countries.

The remainder of the paper is as follows: In the next section, we present our theoretical framework to explain the influence of the country's legal tradition on the information relevance of AGMs. In section 3, we discuss our methodology and dataset. Finally, results and conclusions are presented and discussed in sections 4 and 5 , respectively.

\section{The role of a country's legal tradition}

While the traditional classification of financial and corporate governance systems is based on the institutions' financing firms, La Porta et al. (2000, p. 19) state, '[...] bank- versus market-centeredness is not an especially useful way to distinguish financial systems'. In a previous, and perhaps the most referenced, paper on corporate governance (Richart et al. 2011), La Porta et al. (1998) propose an alternative to the traditional classification based on the legal origin of the countries, the so-called law and finance point of view. The authors analyse 49 mainly developed countries and classify them into two main categories - common-law and civil-law countries - concluding that the former are more effective at protecting outside investors than the latter. Subsequent research has shown that the influence of the legal origin is a valid explanation for financial and accounting differences across countries. As an example, Ball et al. (2000) report that economic losses are more likely to be recognised in the company financial statements in common-law than in civil-law countries. La Porta et al. (2003) show that countries with a French legal origin tend to have relatively weak liability rules as well as weak information disclosure requirements.

La Porta et al. (1998) not only classify countries into common-law and civil-law groups but also establish three different civil-law subgroups: German civil law, Scandinavian civil law, and French civil law. They conclude that common-law countries are more effective at protecting outside investors than civil-law countries, but that French-civil-law countries have the weakest levels of protection and law enforcement, while German and Scandinavian countries fall in between. In fact, the fundamental basis of their argument is precisely that the differences in investor protection determine how the firm is financed and its ownership structure. They also note that ownership concentration is negatively related to the level of investor protection. While, for example, the three largest shareholders concentrate on average $20 \%$ of the ownership of public companies in the U.S. and $19 \%$ in the U.K., civil-law countries such as France (34\%), Italy (58\%), and Spain $(51 \%)$ show much higher levels of ownership concentration. There are several types of ownership concentration, too: Whereas in Germany, banks often take control of corporations through equity holdings and proxy voting mechanisms, family control can be found in many developed countries, including Italy. In Spain, firms and state-owned companies control large companies, whereas individuals and families control mediumsized firms (Leech and Manjón 2002). Japan can be seen as having a special case of ownership, somewhat close to that of Germany. It is known as keiretsu, a system consisting of a network of corporations with crossholdings around a major bank. Generally speaking, ownership concentration reduces agency problems, but managers and majority stockholders tend to expropriate minority stockholders' wealth (the so-called "principal-principal" problem). We understand that the AGM can be used not only to control managers to expropriate shareholders' wealth but also to control for the principal-principal problem. 
The study of Venkataraman et al. (2008) on initial public offerings shows that audit quality is higher in common-law than in civil-law countries, because a stronger demand for high-quality audit reports exists in the former. Finally, DeFond et al. (2007), after analysing the information content of annual earnings announcements in 26 countries, conclude that this content is higher in common-law than in civil-law countries. From this evidence we, therefore, conclude that the quality of audit reports and the content of earnings announcements are lower in civil-law than in common-law countries, as a result of a lower demand for quality information in the former. Similarly, Ball and Shivakumar (2008) show that the quality of firms' financial reports depends on the existing demand for quality reports.

Therefore, the demand for quality information is not independent of a country's legal tradition. We understand that the incremental information provided during the AGM directly depends on the information available before the meeting. In that sense, the more information that is available, the lower the informational impact of the meeting. The main source of information for stockholders prior to the AGM is the notice of convocation. The notice of convocation of the AGM is rather similar across countries in our sample. A standard notice sets the date, time, and location where the AGM will be held and the agenda of the meeting. The items in the agenda are also similar across countries, mainly consisting of the examination and approval of the unconsolidated and consolidated financial statements and audit reports, shareholder compensation, appointment or re-appointment of directors and compensation plans, and re-election of the auditors, among other issues. In addition, we can also find specific board of directors' proposals that require shareholder approval.

Additional information is usually attached to the notice of convocation and the agenda, and it is exactly here that the main differences among countries arise. For example, whereas the documents that must accompany the notice of an AGM of any listed company in the U.S. are extremely detailed (in both paper and Web access formats), the documentation required in France, Germany, or Spain is relatively sparse. U.S. companies must send before the AGM proxy materials and the annual report (regulation 14A of the 1934 Act). The same happens in the U.K., where the notice of the meeting must be accompanied by a copy of the annual accounts of the company, the director's report on the position of the company for the year, and the auditor's report on the accounts (Companies Act, 2006).

On the other hand, civil-law countries, with the exception of Japan, provide information to shareholders by allowing them to examine the documents in the company's registered office or to request that the company send them. In conclusion, we cannot find the same amount of information disclosure before the AGM or the same ease of access to it in civil-law countries. In the specific case of Japanese firms, they send a comprehensive dataset of information containing the date and length of meetings, the number of questions asked and the number of shareholders present; this is available for most publicly traded firms. Japan is closer to the common-law-country level of information disclosure prior to the AGM than that of a civil-law country. This is very much related to preventing sokaiya, corporate extortionists who disrupt meetings to blackmail management; this is done by holding short shareholders' meetings (no more than 30 minutes) where the managers try to control any embarrassing situations that the shareholders may create with their questions to the board. At the same time, the government encourages all companies to hold their AGMs the same day and at the same time to spread the sokaiya manpower over numerous meetings (see table 3). In these circumstances, it is hard to assume that the managers of Japanese firms release any value-relevant information during these meetings.

As said before, when information is released to the market, investors' reaction can be seen in both price and trading volume changes. Market price changes represent overall market expectations (Beaver 1968), whereas trading volume reflects traders' idiosyncratic preference to hold, sell, or buy the shares of a firm (Kim and Verrecchia 1991). Furthermore, high trading volumes around a company event would be associated with the release of new information (Kyle 1985). Accordingly, and following the Brown and Warner (1985) (BW) methodology, the null hypotheses have been posited:

Hypothesis 1: In a civil- or common-law country, stock returns on the day of the AGM will not differ from those on ordinary days.

Hypothesis 2: In a civil- or common-law country, volatility stock returns on the day of the AGM will not differ from those on ordinary days.

Hypothesis 3: In a civil- or common-law country, the volume of shares traded on the day of the AGM will not differ from that on ordinary days.

While the AGM agenda is almost the same for all the countries belonging to our sample, we would expect the incremental informational content of the AGM to be different in common-law and civil-law countries. In common-law countries, we could expect that, given the amount of information attached to the notice of convocation, the shareholder meeting reveals less additional value-relevant information than in civil- 
law countries, where shareholders have access to a small amount of information before the meeting, with the exception of Japan, where sokaiya prevention makes it difficult to transmit any relevant information to the financial market.

\section{Methodology}

In subsections 3.1 and 3.2, we present the sample and dataset used in our research and the methodology we propose to address the informational content of the AGM.

\subsection{Sample and dataset}

To accomplish our goal, we examine abnormal stock prices and trading volumes around the AGM in France, Germany, Japan, Spain, the U.K., and the U.S., from January 2005 to June 2010. Table 1 shows the stock index, number of companies, and events, on a country basis. We select all companies belonging to each country index with the exception of the FTSE All-Share Index. In that case, the 30 largest companies by market capitalisation in December 2010 form the sample to make the sample size and firm capitalisation characteristics comparable among countries. Table 2 reports the average summary statistics of financial and institutional variables corresponding to the analysed period by country.

Daily trading data were obtained from the Thomson Reuters 3000 Xtra database, and information about the AGM dates was hand-collected from each country's stock market regulatory organism, as a first approach. When the date of the AGM was missing in our primary source, it was obtained from the company's corporate website.

[Insert table 1]

[Insert table 2]

\subsection{Methodology}

We have followed the BW (1985) event study methodology to assess the information content of the AGM in countries with different legal traditions.

We have tested the aggregate market's average reaction to the information released by testing the change in price through two different measures: abnormal returns (ARs) and the absolute value of abnormal returns (AAAR). Additionally, we have tested the sum of all individual investors' trades around AGM dates by analysing the change of trading volumes. The three indicators of the market reaction to the release of information have been tested individually for each country in our sample.

We compute ARs as the difference between actual and normal returns, while normal returns are defined as the expected return without conditioning on the event.

The return of security $i$ over period $t$ is defined as

$R_{i t}=E\left(R_{i t} \mid X_{t}\right)_{i t}+\mathrm{AR}_{i t}$

where $R_{i t}, E\left(R_{i t} \mid X_{t}\right)_{i t}$, and $\mathrm{AR}_{i t}$ are the actual, normal, and abnormal returns, respectively. $X_{\mathrm{t}}$ is the conditioning information set for the normal return model. We compute expected or normal returns using the market model; thus, we assume that normal return is given by a linear relationship between the stock return and the market return:

$$
\begin{aligned}
& E\left(R_{t t} \mid X_{t}\right)_{i t}=a_{i}+b_{i} R_{m t} \\
& R_{m t}=\ln \left(\frac{\text { Countrylndex }_{t}}{\text { Countrylndex }_{t-1}}\right) \\
& \text { a and b estimated parameters }
\end{aligned}
$$

We estimate the security normal returns through a pre-event period of 151 days from day -170 to day 20, with day 0 being the AGM day. 
Given the nature of the event, it is meaningful to address the behaviour of prices and trading volumes before and after the AGM. Under insider trading, we should observe a market reaction before the AGM, while it could be also possible that the market reacts with a delay to the information released during the AGM. To capture these possible effects, we have not limited our research to the day of the event but have also examined an 11-day event window $[-5,+5]$.

After estimating daily average abnormal returns (AARs) for each firm, the AAR for each country's whole sample on day $t\left(\mathrm{AAR}_{t}\right)$ is calculated:

$$
A A R_{t}=\frac{1}{N} \sum_{i=1}^{N} A R_{i t}
$$

The $t$-statistic for AAR at any day in the event period is given by

$$
t-\text { statistic }=\frac{A A R_{t}}{S_{p}}
$$

where $S_{p}$ is the standard deviation of the AR over the pre-event period.

The cumulative average abnormal return (CAAR) is obtained by adding the average daily AR for different time intervals $(a, b)$, within the event window $[-5,+5]$ :

$$
C A A R=\sum_{t=a}^{b} A A R_{t}
$$

For each country sample, a large number of events have been studied. Unless all the companies experience the same positive or negative reaction to the AGM, positive and negative ARs would cancel each other out, which would imply that we would not be able to detect changes in prices. To avoid this problem, we also examine the stock price volatility around the AGM, measured as the AAAR, and then proceed in a manner similar to how we handled ARs. The only difference arises in how ARs are computed: when ARs are computed as absolute values, they cannot be directly used to perform a parametric test because the null hypothesis, that a sum of absolute values is zero, will be rejected. Therefore, we correct absolute returns by the mean value of the pre-event period.

Following Menendez (2005), we define abnormal trading volumes for stock $i$ on day $t$ as

$$
A V_{i t}=\frac{V_{i t}}{\left(\sum_{t=-94}^{-20} V_{i t}+\sum_{t=30}^{104} V_{i t}\right) \times \frac{1}{150}}
$$

where $V_{i t}$ is the traded volume in euros of stock $i$ on day $t$.

As we did with returns, once abnormal daily volumes have been computed for each firm, the average abnormal trading volume (AAV) on day $\boldsymbol{t}$ is calculated as

$$
A A V_{i}=\frac{1}{N} \sum_{i=1}^{N} A V_{i t}-1
$$

The $t$-statistic for AAV is given by

$$
t-\text { statistic }=\frac{A A V_{t}}{S_{p}}
$$


The cumulative average abnormal volume (CAAV) is obtained by adding average daily abnormal volumes across different time intervals $(a, b)$, within the event window $[-5,+5]$ :

$$
C A A V=\sum_{t=a}^{b} A A V_{t}
$$

The three null hypotheses are tested through both parametric and non-parametric tests. For the parametric test, BW methodology is followed. Additionally, we have performed Corrado's (1989) nonparametric rank test. To implement the rank test, we first transform each firm's AR in ranks $\left(K_{i}\right)$ over the combined period, including the estimation and the event window $\left(T_{i}\right)$.

$$
\begin{aligned}
& K_{i l}=\operatorname{rank}\left(A R_{i l}\right) \\
& A R_{i l}>A R_{i s} \Rightarrow K_{i l}>K_{i s}
\end{aligned}
$$

The test compares the ranks in the event period for each firm, with the expected average rank under the null hypothesis of no ARs. The test statistic for the null hypothesis is:

$$
R=\frac{\frac{1}{N} \sum_{i=1}^{N}\left(K_{i 0}-\overline{K_{i}}\right)}{S(\bar{K})}
$$

where

$$
S(\bar{K})=\sqrt{\frac{1}{T}} \sum_{t=1}^{T} \frac{1}{N^{2}} \sum_{i=1}^{N}\left(K_{i t}-\bar{K}_{i}\right)^{2}
$$

In BW (1985), the authors conducted simulated event studies and concluded that estimates from ordinary least squares with a market index tested with parametric statistical tests were well specified with random samples. Ahern (2009) conducted simulations of event studies with samples grouped by size, prior returns, and book-to-market and earning-to-price ratios, concluding that standard event study methods produce statistical biases in grouped samples. Moreover, he points out that 'the power of the $t$-test to detect abnormal performance is lower than the non-parametric tests and displays considerable bias' (Ahern 2009, p. 480). In our research, although both tests are performed, since we are analysing a grouped sample with a likely size effect on the results, we give more credit to the results reported by the non-parametric test.

Time independency is a key factor in event studies. It is well known that event studies are predisposed to cross-sectional correlation among ARs when the event day is the same for all the firms in the sample. This situation is defined as clustering, and it causes serious over-rejection of the null hypothesis (Kolari and Pynnonen 2010). Table 3 shows the distribution of AGM dates from 2005 to 2010 in Japan. As an example, $80 \%$ of the AGMs took place in only four days in 2009 and 2010. Therefore, since time independency is clearly rejected in Japan, the $t$-test would be misspecified. As suggested by Kolari and Pynnonen (2010) for situations involving clustering, Corrado and Zivney's (1992) non-parametric test has been applied in the specific case of Japan.

[Insert table 3]

We have tested the robustness of our results by constructing AR and AV final panels applying both the average and the median. Only a very small number of significance values change by applying the median, and they do not affect any main result that could change our conclusions. The results shown in the next section are based on average values.

\section{Results}

Results are presented in six tables, one per country, following the same structure. Each table is divided into three panels showing AAR (panel 1), AAAR (panel 2), and AAV (panel 3) results and significance levels for both the $t$-statistic and Corrado test.

The bottom of each table shows cumulative results for four distinct periods. Thus, accumulated results are presented considering the day of the event as well as previous days in the window [-5, 0], one day before [- 
$1,0]$, one day after $[0,1]$, and the post-event $[0,+5]$ accumulated effect. The first period analysed measures whether there is leakage of information prior to the AGM, the last determines the delayed reaction in time, and the second and the third, very common in the literature, reflect a very short-term anticipated or delayed reaction to the AGM.

Results are by group, taking into account the countries' legal traditions, as seen in section 2 .

\subsection{Stock prices and trading volumes around the AGM in common-law countries}

Tables 4 and 5 summarise the results for the U.K. and U.S. samples, respectively.

\section{[Insert table 4]}

[Insert table 5]

For the shareholders' meeting date, the parametric and non-parametric tests show no evidence of price changes in both measures for the U.K. and U.S. samples for the event window days. Thus, the AGM does not affect returns or returns volatility, and the two null hypotheses cannot be rejected in our common-law subset of countries. The same result applies to changes in prices before the AGM, characterised by no significant abnormal results. The main conclusion regarding ARs and AAARs is that market expectations do not change because of shareholders' meetings; thus, the AGM does not seem to provide relevant information to the financial market in these two common-law countries. These findings are in line with Firth's (1981) results and do not directly contradict Rippington and Taffler's (1995) and Olibe's (2002) main conclusions for the U.K. that shareholders' meetings convey little information to the market. On the other hand, our results partially contradict the findings of Brickley (1985), whose work was the only research supporting a clear effect of the AGM on stock prices in the U.S. Although we are comparing our results with previous research, we have to be cautious since the companies examined in the references cited were operating in a totally different information environment, thus limiting the comparability of results.

For the multi-day tests, CAAR is statistically significant for the sub-periods $[-5,0]$ and $[-1,0]$ for the U.S. sample, indicating a negative market reaction prior to the AGM. Cumulative average absolute value of abnormal return (CAAAR) $[-1,0]$ is also significant for the U.K. sample with the Corrado test indicating an increase in volatility. Given that we cannot find a significant CAAR for the same sub-period, the increase in volatility indicates that the U.K. market finds the event informative but does not interpret the information equally. It is worth mentioning that CAAR for $[-1,0]$ in the U.K. is also negative, although not significant.

These results indicate that although there is not an aggregate market reaction on a day-by-day basis, the AGM provided some information to the market in the U.S. and the U.K., since the period [-1, 0] shows a significant change in prices.

For the day-by-day analysis, panel 3 provides evidence of significant above-average trading activity on AGM days for both the U.K. and U.S. samples, which means that the third null hypothesis has to be rejected. Moreover, we observe significantly abnormal trading volumes on $t=-1$ and $t=-5$ for the U.K. and on $t=-3$ and $t=-4$ for the U.S., which can be understood as an anticipated response to the AGM. When trading response is accumulated across days, the evidence of higher trading volumes is sustained in each of the four sub-periods studied. It is worth noting that abnormal trading volumes, on a day-by-day basis, are always positive within the event window. In these two common-law countries, our analysis suggests that investors review their beliefs after the AGM.

Accordingly, they take actions resulting in abnormal and statistically significant trading volumes. In the specific case of the U.S., the negative sign in CAAR indicates that they agree about selling their stocks, whereas in the U.K., CAAAR indicates that they do not agree about selling or buying.

\subsection{Stock prices and trading volumes around the AGM in civil-law countries}

As shown in section 2, a close relation exists between investor protection and information quality; hence, we show the results for Germany, Japan, France, and Spain in pairs.

First, we discuss the price and volume response results for Germany and Japan, both countries belonging to the German-civil-law subgroup. Next, results are provided for France and Spain, as they belong to the French-civil-law subgroup.

\subsubsection{Germany and Japan}

Following our results in table 6 (panels 1 and 2), we reject null hypotheses 1 and 2 of price changes around the AGM in the German stock market. These hypotheses are rejected through both parametric and nonparametric tests. Our results show not only positive and significant price changes on the day of the AGM but also a serious correction the day after, with a significant increase in volatility and a negative AR on $t=+1$. The 
return reaction lasts for several days and the multi-day CAAR $[0,+5]$ is negative and statistically significant, suggesting a financial market overreaction to the information released during the AGM and a subsequent correction after the meeting. The behaviour of CAAAR also indicates a significant increase in returns volatility during the periods $[0,+1]$ and $[0,+5]$.

Panels 1 and 2 in table 7 present AAR and AAAR around AGM dates in Japan. As can be seen, the Corrado test does not support a significant reaction of stock prices to the AGM; thus, the two null hypotheses concerning price changes cannot be rejected for the Japanese stock market. The AGM does not seem to convey, on average, any value-relevant information to the financial market. Table 7 also reports significantly lower levels of volatility after the AGM, thus supporting the lack of relevant information releases during shareholder meetings. It is worth noting that this result is reported for each day within the event window. The lack of any informational effect in the Japanese market lasts for several days, as detected by CAAAR, showing significant and lower-than-average levels of volatility. This result is consistent with sokaiya preventions taken by corporate managers in Japan.

It is interesting to compare our results for Germany and Japan. Although both countries belong to the same group in La Porta et al.'s (1998) classification scheme, our results regarding AAR and AAAR for the two countries have very little in common. The fact that we report an average market reaction to the AGM in Germany but not in Japan emphasises the relevance of institutional issues in addition to a country's legal tradition

[Insert table 6]

[Insert table 7]

Trading volumes around AGM dates in Germany and Japan are reported in panel 3 of tables 6 and 7. As was the case with stock prices, trading volumes around AGM dates show quite different behaviours in the two countries. Shareholder meetings do not seem to have any effect on stock trading volumes in Japan, where the results show systematic, although not significant, lower-than-average trading activity for each day within the event window. Consequently, null hypothesis 3, stating that trading volumes will not be affected by the AGM, cannot be rejected for Japan. Although a day-by-day analysis does not detect any significant change in trading volumes, CAAV is significant and lower than average for three sub-periods analysed: before, around, and after the AGM day.

Conversely, results for the German market show large and statistically significant trading volumes for six out of seven days within sub-period $[-5,+1]$. Therefore, null hypothesis 3 concerning trading volumes is rejected for Germany.

We conclude that investors seem to adjust their investment portfolio decisions before, during, and after the AGM in Germany. We can also say that the AGM does not fulfil their expectations because before and during the meeting we obtain positive ARs, which are corrected with a very strong negative reaction after the meeting. Our results indicate that relevant information, as expected, is transmitted to the financial market during the AGM in Germany. The increase in law enforcement to protect investors in Germany, where its managers face a wide scope of criminal sanctions, maximum fines, and prison terms, compared with other civil-law and even common-law countries, may explain a part of it (Djankow et al. 2008).

\subsubsection{France and Spain}

Changes in stock prices in France and Spain are reported in tables 8 and 9 (panels 1 and 2), respectively. Neither AAR nor AAAR on AGM dates is statistically significant in either of the two markets. Thus, neither of the two null hypotheses regarding price changes can be rejected for France or Spain. Although both countries show the same results regarding the day of the AGM, this is not the case for the days around the AGM. On the one hand, in the French sample, we cannot find any price anticipation of the meeting, whereas in the Spanish sample, we detect positive and statistically significant ARs on $t=-3$ and $t=-1$, and negative significant abnormal volatility on $t=-3$. On the other hand, a delayed reaction of stock prices to the AGM is reported in France, where negative and statistically significant ARs are observed on $t=+2, t=+4$, and $t=+5$, with above-average volatility on $t=+2$ and $t=+5$. Such behaviour is not observed in the Spanish market, where stock prices do not show any particular behaviour on days after the AGM. The analysis of cumulative ARs reinforces our previous conclusion.

[Insert table 8]

[Insert table 9]

The analysis of trading volumes in France confirms above-average trading activity on the day of the AGM and the day after. The $t$-statistic and the Corrado test provide similar results. These results are extendible to days $t=+4$ and $t=+5$, indicating that the increase in trading volumes induced by the AGM lasts for several 
days. Therefore, the null hypothesis that states that trading volumes are not affected by the AGM is rejected in the French case. Regarding the Spanish market, the $t$-statistic and the Corrado test lead to contradictory results. Based on the $t$-statistic, trading volume on the day of the AGM is positive and statistically significant, although this result is not supported by the Corrado test. As discussed in the methodology section, the Corrado test performs better than the $t$-statistic when a sample is not randomly selected; thus, we finally conclude that the AGM in Spain does not affect trading volumes. Therefore, we cannot reject the third null hypothesis in Spain. These results are in line with previous investigations (Garcia-Blandon et al. 2012) that find no abnormal trading activity in Spain during the AGM. Abnormal trading volume is detected on days $t=+2$ and $t=+5$, confirmed by the $t$-statistic and the Corrado test, as a late reaction to the information released during the meeting.

We conclude that no relevant information is given to the overall market during the AGM in Spain, supporting the lack of information content of this corporate event. We can point out a plausible explanation based on ownership structure in Spain. As it is quite concentrated, it makes it easier for managers to communicate with the most important shareholders, leaving out the event from any relevant content.

Table 10 reports a summary of three indicators of the market reaction to the information released during the AGM. As can be appreciated, the U.K. and the U.S. show identical reactions, while the civil-law countries exhibit very different behaviours. In fact, the financial market in France shows a reaction identical to that of the U.K. and the U.S., and it is not comparable to any other country within the civil-law group. Spain and Japan show no reaction to the AGM, but the most jarring case is that of Germany, whose reaction is not comparable to any of the countries analysed.

[Insert table 10]

\section{Conclusions}

The main goal of this paper has been to analyse whether the informational content of the AGM depends on a country's legal tradition. Following our results, this question has a partial positive answer. The two common-law countries in our sample, the U.S. and the U.K., show very similar reactions to the AGM for returns, returns volatility, and trading volumes. Returns and volatility do not seem to be affected by the AGM, thus indicating that no relevant information for the overall market is released during these meetings. Nevertheless, we observe a significant increase in the number of shares traded before and on AGM dates, therefore suggesting that these meetings are not irrelevant for individual investors. The lack of reaction of stock prices to the AGM contradicts most of the evidence available for the two countries, showing a moderate effect of the AGM on stock prices. In our opinion, the dilution of the AGM effects in recent times is due to the fact that both the quantity and the quality of the information publicly available are much higher than they were several decades ago. Therefore, the marginal informational content of the AGM is not on average relevant for the market.

Contrary to our expectations, we have found that we cannot generalise the AGM as an informative event in civil-law countries as we do for the U.S. and the U.K. Our results emphasise the role of national idiosyncratic characteristics beyond legal tradition on the information transmitted during the AGM within the civil-law group of countries. The effects of the AGM on the behaviour of stocks importantly differ across countries, being particularly distinctive in Germany, which is the only civil-law country where our expectations are fulfilled. German stocks are characterised by a dramatic change in stock prices and volume traded on the day of the AGM, suggesting that relevant information is transmitted for the overall market and for individual investors. In the French market, our expectations are fulfilled only partially because the AGM only transmits relevant information for individual investors. As information available before the AGM is sparse, we shall assume that the information transmitted during the meeting is already known, somehow, by the overall market, or is irrelevant. On the other hand, we do not observe any reaction in Japan and Spain. Although the lack of reaction was expected in the former, where the AGM is clearly a dispensable tool as a source of information, the latter results are quite surprising. In Japan, the information available before the meeting is extensive and detailed, and thus we understand that the lack of information during the meeting is not the ideal situation but is less harmful to investors. However, Spain shows a very low level of information disclosure before and during the meeting, which indicates this is not a source of relevant information. From our point of view, this is the worst possible situation, with no information transmitted during the meeting.

\section{Acknowledgement}

The authors would like to thank the reviewers for their comments that helped to improve the manuscript. 


\section{References}

Ahern, K.R. (2009). Sample selection and event study estimation. Journal of Empirical Finance, 16, 466-482.

Ball, R., Kothari, S., Robin, A. (2000). The effect of international institutional factors on properties of accounting earnings, Journal of Accounting and Economics, 29, 1-51.

Ball, R., Shivakumar, L. (2008). Earnings quality at initial public offerings. Journal of Accounting and Economics, 45 (2-3), 324-349.

Beaver, W. (1968). The information content of annual earnings announcements. Journal of Accounting Research, 6, 67-92.

Brickley, J. (1985). Interpreting common stock returns around proxy statement disclosures and annual shareholder meetings, Journal of Financial and Quantitative Analysis, 25 (3), 343-349.

Brown, S., Warner, J. (1985). Using daily stock returns: The case of event studies. Journal of Financial Economics, 14, 3-31.

Catasus, B., Johed, G. (2007). Annual general meetings-rituals of closure or ideal speech situations? A dual analysis. Scandinavian Journal of Management, 23 (2), 168-190.

Corrado, C. (1989). A nonparametric test for abnormal security-price performance in event studies. Journal of Financial Economics, 23, 385-95.

Corrado, C.J., Zivney, T.L. (1992). The specification and power of the sign test in Event Study hypothesis tests using daily stock returns. Journal of Financial and Quantitative Analysis, 27 (3), 465-478.

Cziraki, P., Renneboog, L., Szilagyi, P. (2010). Shareholder activism through proxy proposals: The European perspective. European Financial Management, 16 (5), 738-777.

DeFond, M., Hung, M., Trezevant, R. (2007). Investor protection and the information content of annual earnings announcements: international evidence. Journal of Accounting and Economics, 43 (1), 37-67.

Djankov, S., La Porta, R., Lopez-de-Silanes, F., Shleifer, A. (2008). The law and economics of self-dealing. Journal of Financial Economics, 88, 430-465.

Firth, M. (1981). The relative information content of the release of financial results data by firms, Journal of Accounting Research, 19 (2), 521-529.

Garcia-Blandon, J., Martinez-Blasco, M., Argiles-Bosch, J.M. (2011). The role of annual general meetings in a civil-law country. In Kose, J., Makhija, A.K. (Ed.), International Corporate Governance (Advances in Financial Economics, vol. 14.), pp. 87-108. UK: Emerald Group Publishing Limited.

Garcia-Blandon, J., Martinez-Blasco, M., Argiles-Bosch, J.M. (2012). Does the Annual General Meeting involve the release of relevant information in non-common law markets? Evidence from Spain. Revista Española de Financiación y Contabilidad. 153, 209-232.

Kalay, A., Loewenstein, U. (1985). Predictable events and excess returns: the case of dividend announcement. Journal of Financial Economics, 14, 423-49.

Kim, O., Verrecchia, R. E. (1991). Trading volume and price reactions to public announcements. Journal of Accounting Research, 29(2), 302-321.

Kolari, J.W., Pynnonen, S. (2010). Event study testing with cross-sectional correlation of abnormal returns. The Review of Financial Studies, 23 (11), 3996-4025.

Kyle, A. (1985). Continuous auctions and insider trading, Econometrica, 53, 1315-35.

La Porta, R., Lopez-de-Silanes, F., Shleifer, A., Vishny, R. (1998). Law and finance. Journal of Political 
Economy, 106, 1113-1155.

La Porta, R., Lopez-de-Silanes, F., Shleifer, A., Vishny, R. (2000). Investor protection and corporate governance. Journal of Financial Economics 58, 3-27.

La Porta, R., Lopez-de-Silanes, F., Pop-Eleches, C., Shleifer, A. (2003). Judicial checks and balances. National Bureau of Economic Research Working Paper 9775.

Leech, D., Manjon, M.C. (2002). Corporate governance in Spain (with an application of the power indices approach). European Journal of Law and Economics, 13, 157-173.

Menendez, S. (2005). Market valuation of the analysts' recommendations: the Spanish stock market. Applied Financial Economics, 15, 509-518.

Olibe, K.O. (2002). The information content of anual general meetings: a price and trading volume analysis. Journal of International Accounting, Auditing and Taxation, 11, 19-37.

Richart-Ramón, A., Martínez-Blasco, M., García-Blandón, J. (2011). Análisis de la Producción Científica sobre Gobierno Corporativo a través de ISI Web of Science. Revista Española de Documentación Científica, 34(1), 79-101.

Rippington, F., Taffler, R. (1995). The information content of firm financial disclosures. Journal of Business Finance and Accounting, 22 (3), 345-362.

Stratling, R. (2003). General meetings: A dispensable tool for corporate governance of listed companies?. Corporate Governance: An International Review, 11, 74-82.

Venkataraman, R. Weber, J., Willenborg, M. (2008). Litigation risk, audit quality, and audit fees: Evidence from initial public offerings. The Accounting Review, 83 (5), 1315-1345. 
Table 1 This table presents the stock indexes, number of companies, and events per country in our sample.

\begin{tabular}{|l|c|c|c|}
\hline Country & Stock Index & $\begin{array}{c}\text { Number of } \\
\text { companies }\end{array}$ & Number of events \\
\hline France & CAC40 & 40 & 180 \\
\hline Germany & DAX30 & 30 & 176 \\
\hline Japan & Nikkei & 30 & 198 \\
\hline Spain & IBEX35 & 35 & 180 \\
\hline U.K. & FTSE All-Share & 30 & 180 \\
\hline U.S. & DJIA & 30 & 1,148 \\
\hline Total & & 195 & \\
\hline
\end{tabular}


Table 2 This table reports the average summary statistics for the six years period analysed, unless for growth in revenues.

Market capitalization, Revenues and EBITDA are expressed in millions of US dollars

Growth in revenues is estimated as the geometrical average of the past three years historical growth in revenues.

ROE=Return on Equity. Estimated by dividing the Net Income by the book value of Equity.

ROC=Return on Capital. Estimated by dividing After Tax Operating Income by the book value of previous year invested capital.

Institutional holding=Percentage of outstanding shares being held by mutual funds, pension funds and trusts.

\begin{tabular}{|c|c|c|c|c|c|}
\hline & Minimum & Median & Mean & Maximum & Stand.dev. \\
\hline & \multicolumn{5}{|c|}{ France } \\
\hline Market Capitalization & $5,279.05$ & $28,280.00$ & $39,083.90$ & $204,632.50$ & $34,289.39$ \\
\hline Revenues & 698.97 & $24,511.70$ & $39,180.34$ & $224,035.50$ & $38,356.96$ \\
\hline EBITDA & 130.48 & $3,951.35$ & $6,128.91$ & $46,900.00$ & $7,369.72$ \\
\hline Growth in revenues (2009-2010) & -0.13 & 0.03 & 0.03 & 0.24 & 0.07 \\
\hline ROE & -0.47 & 0.13 & 0.12 & 0.49 & 0.12 \\
\hline $\mathrm{ROC}$ & -0.11 & 0.12 & 0.14 & 0.97 & 0.12 \\
\hline \multirow[t]{2}{*}{ Institutional holding (2009-2010) } & 0.04 & 0.35 & 0.35 & 0.67 & 0.14 \\
\hline & \multicolumn{5}{|c|}{ Germany } \\
\hline Market Capitalization & $6,027.60$ & $24,075.41$ & $36,442.18$ & $156,449.40$ & $28,317.79$ \\
\hline Revenues & $1,955.51$ & $33,821.49$ & $48,685.08$ & $207,490.36$ & $44,699.72$ \\
\hline EBITDA & -191.60 & $3,643.60$ & $6,011.02$ & $28,266.60$ & $6,150.25$ \\
\hline Growth in revenues (2009-2010) & -0.12 & 0.03 & 0.03 & 0.21 & 0.07 \\
\hline ROE & -1.76 & 0.12 & 0.12 & 0.42 & 0.18 \\
\hline $\mathrm{ROC}$ & -0.18 & 0.10 & 0.14 & 1.12 & 0.16 \\
\hline \multirow[t]{2}{*}{ Institutional holding (2009-2010) } & 0.07 & 0.36 & 0.37 & 0.65 & 0.13 \\
\hline & \multicolumn{5}{|c|}{ Japan } \\
\hline Market Capitalization & $15,868.80$ & $33,226.11$ & $45,428.56$ & $240,099.20$ & $34,301.28$ \\
\hline Revenues & $2,711.10$ & $36,566.47$ & $47,292.54$ & $207,484.80$ & $37,982.60$ \\
\hline EBITDA & 226.70 & $5,709.88$ & $7,498.64$ & $33,576.80$ & $6,686.56$ \\
\hline Growth in revenues (2009-2010) & -0.15 & -0.04 & -0.03 & 0.16 & 0.06 \\
\hline ROE & -0.45 & 0.10 & 0.09 & 0.43 & 0.10 \\
\hline ROC & -0.08 & 0.07 & 0.10 & 0.50 & 0.10 \\
\hline \multirow[t]{2}{*}{ Institutional holding (2009-2010) } & 0.08 & 0.23 & 0.26 & 0.67 & 0.12 \\
\hline & \multicolumn{5}{|c|}{ Spain } \\
\hline Market Capitalization & 220.00 & $8,360.83$ & $21,008.89$ & $160,930.10$ & $30,009.31$ \\
\hline Revenues & 30.70 & $5,285.67$ & $12,964.67$ & $83,325.60$ & $17,916.08$ \\
\hline EBITDA & -275.60 & $1,005.59$ & $2,852.37$ & $32,098.90$ & $5,239.50$ \\
\hline Growth in revenues (2009-2010) & -0.17 & 0.05 & 0.08 & 1.30 & 0.21 \\
\hline ROE & -0.17 & 0.18 & 0.20 & 0.66 & 0.12 \\
\hline $\mathrm{ROC}$ & -0.17 & 0.08 & 0.11 & 0.68 & 0.12 \\
\hline \multirow[t]{2}{*}{ Institutional holding (2009-2010) } & 0.01 & 0.25 & 0.26 & 0.92 & 0.19 \\
\hline & \multicolumn{5}{|c|}{ U.S. } \\
\hline Market Capitalization & $7,515.00$ & $110,952.00$ & $124,215.72$ & $511,719.20$ & $88,637.21$ \\
\hline Revenues & $18,439.00$ & $51,210.00$ & $85,570.64$ & $425,071.00$ & $90,874.17$ \\
\hline EBITDA & 359.00 & $11,505.10$ & $22,220.49$ & $111,115.00$ & $22,710.74$ \\
\hline Growth in revenues & -0.44 & 0.08 & 0.07 & 0.69 & 0.14 \\
\hline ROE & -0.08 & 0.20 & 0.23 & 1.20 & 0.15 \\
\hline $\mathrm{ROC}$ & -0.05 & 0.17 & 0.24 & 1.91 & 0.26 \\
\hline \multirow[t]{2}{*}{ Institutional holding (2009-2010) } & 0.13 & 0.65 & 0.65 & 0.86 & 0.11 \\
\hline & \multicolumn{5}{|c|}{ U.K. } \\
\hline Market Capitalization & $6,341.19$ & $48,794.52$ & $65,949.39$ & $224,674.40$ & $55,441.83$ \\
\hline Revenues & $2,962.60$ & $30,906.10$ & $49,111.63$ & $524,657.44$ & $79,643.86$ \\
\hline EBITDA & $-2,640.10$ & $5,991.72$ & $10,355.17$ & $71,645.94$ & $12,572.37$ \\
\hline Growth in revenues (2009-2010) & -0.53 & 0.09 & 0.08 & 0.67 & 0.17 \\
\hline ROE & -0.44 & 0.25 & 0.30 & 1.00 & 0.25 \\
\hline ROC & -0.70 & 0.17 & 0.21 & 1.02 & 0.22 \\
\hline
\end{tabular}


Institutional holding (2009-2010) 
Table 3 This table shows the AGM distribution dates in Japan from 2005 to 2010 to illustrate how the AGM celebration dates are coincident around the $20^{\text {th }}$ and $29^{\text {th }}$ of June.

\begin{tabular}{|c|c|c|c|c|c|c|c|}
\hline & 2005 & 2006 & 2007 & 2008 & 2009 & 2010 & Total \\
\hline 27-Mar & & & & & 1 & & 1 \\
\hline 28-Mar & & & & 1 & & & 1 \\
\hline 29-Mar & & & 1 & & & & 1 \\
\hline 30-Mar & 1 & 1 & & & & 1 & 3 \\
\hline 22-May & & & & 1 & & & 1 \\
\hline 24-May & & & 1 & & & & 1 \\
\hline 25-May & & 1 & & & & & 1 \\
\hline 27-May & & & & & & 1 & 1 \\
\hline 28-May & & & & & 1 & & 1 \\
\hline 15-Jun & & 1 & & & & & 1 \\
\hline 17-Jun & & & & & & 1 & 1 \\
\hline 18-Jun & & & & & 1 & 1 & 2 \\
\hline 19-Jun & & & & 1 & 1 & & 2 \\
\hline 20-Jun & & & 2 & 2 & & & 4 \\
\hline 21-Jun & 1 & & 1 & & & & 2 \\
\hline 22-Jun & 3 & 1 & 7 & & & 1 & 12 \\
\hline 23-Jun & 2 & 7 & & 1 & 6 & 5 & 21 \\
\hline 24-Jun & 6 & & & 6 & 9 & 7 & 28 \\
\hline 25-Jun & 1 & & 3 & 8 & 4 & 5 & 21 \\
\hline 26-Jun & & & 5 & 4 & 5 & & 14 \\
\hline 27-Jun & & 6 & 2 & 5 & 1 & & 14 \\
\hline 28-Jun & 5 & 7 & 7 & 1 & & 1 & 21 \\
\hline 29-Jun & 7 & 6 & 1 & & 1 & 7 & 22 \\
\hline Total & 26 & 30 & 30 & 30 & 30 & 30 & \\
\hline
\end{tabular}


Table 4 This table summarizes daily average abnormal returns, absolute value abnormal returns, and abnormal trading volumes around annual general meeting dates in the U.K. It also shows cumulative results at the bottom. Superscript $* * *$ and $* *$ indicate significance at $1 \%$ and $5 \%$ levels, respectively.

\begin{tabular}{|c|c|c|c|c|c|c|c|c|c|c|c|}
\hline \multirow[b]{2}{*}{ Day } & \multicolumn{3}{|c|}{ Panel 1} & \multicolumn{3}{|c|}{ Panel 2} & \multicolumn{5}{|c|}{ Panel 3} \\
\hline & AAR & t-stat & Corrado & AAAR & t-stat & Corrado & AAV & t-stat & & Corrado & \\
\hline-5 & -0.0008 & -0.4533 & -0.7523 & 0.0010 & 0.8461 & 0.4191 & 0.1815 & 2.3463 & $*$ & 1.9818 & $*$ \\
\hline-4 & 0.0011 & 0.6174 & 0.4594 & -0.0011 & -0.8825 & -0.9564 & 0.1252 & 1.6184 & & 1.3257 & \\
\hline-3 & -0.0010 & -0.5827 & -1.0851 & -0.0007 & -0.5445 & 0.1284 & 0.0957 & 1.2374 & & 1.3635 & \\
\hline-2 & 0.0011 & 0.6156 & 0.6872 & -0.0002 & -0.1249 & 0.3718 & 0.1028 & 1.3292 & & 1.3034 & \\
\hline-1 & -0.0003 & -0.1736 & -0.6800 & 0.0009 & 0.7080 & 1.5411 & 0.1992 & 2.5746 & $*$ & 2.5513 & $*$ \\
\hline 0 & -0.0014 & -0.7716 & -1.7760 & 0.0014 & 1.1174 & 1.6628 & 0.3241 & 4.1887 & $*$ & 2.7470 & $*$ \\
\hline 1 & 0.0001 & 0.0365 & -0.1555 & -0.0010 & -0.8050 & -0.6928 & 0.1475 & 1.9069 & & 1.5881 & \\
\hline 2 & 0.0006 & 0.3539 & 0.4594 & 0.0006 & 0.4958 & 0.2433 & 0.0726 & 0.9381 & & 0.7985 & \\
\hline 3 & -0.0001 & -0.0322 & -0.5136 & -0.0005 & -0.4209 & 0.1893 & 0.0353 & 0.4566 & & 0.1268 & \\
\hline 4 & -0.0006 & -0.3313 & -0.2098 & -0.0008 & -0.6123 & -0.7097 & 0.0692 & 0.8945 & & 0.9720 & \\
\hline 5 & 0.0011 & 0.6087 & 0.1302 & 0.0004 & 0.2934 & 0.7030 & 0.0662 & 0.8561 & & 0.4026 & \\
\hline$[-5,0]$ & -0.0013 & -0.3055 & -1.2847 & 0.0014 & 0.4570 & 0.6788 & 1.0286 & 5.4275 & $* *$ & 4.6020 & $* *$ \\
\hline$[-1,0]$ & -0.0017 & -0.6684 & -1.7366 & 0.0023 & 1.2907 & $2.2655 *$ & 0.5233 & 4.7824 & $* *$ & 3.7464 & $* *$ \\
\hline$[0,1]$ & -0.0013 & -0.5198 & -1.3658 & 0.0004 & 0.2209 & 0.6859 & 0.4716 & 4.3103 & $* *$ & 3.0654 & $* *$ \\
\hline$[0,5]$ & -0.0002 & -0.0556 & -0.8432 & 0.0001 & 0.0279 & 0.5698 & 0.7150 & 3.7726 & $* *$ & 2.7087 & $* *$ \\
\hline
\end{tabular}


Table 5 This table summarizes daily average abnormal returns, absolute value abnormal returns, and abnormal trading volumes around annual general meeting dates in the U.S. It also shows cumulative results at the bottom. Superscript $* * *$ and $* *$ indicate significance at $1 \%$ and $5 \%$ levels, respectively.

\begin{tabular}{|c|c|c|c|c|c|c|c|c|c|c|c|}
\hline \multirow[b]{2}{*}{ Day } & \multicolumn{3}{|c|}{ Panel 1} & \multicolumn{3}{|c|}{ Panel 2} & \multicolumn{5}{|c|}{ Panel 3} \\
\hline & AAR & t-stat & Corrado & AAAR & t-stat & Corrado & AAV & t-stat & & Corrado & \\
\hline-5 & -0.0028 & $-2.5928 \quad * *$ & -1.5718 & 0.0014 & 1.5384 & 0.4240 & 0.1069 & 1.7432 & & 1.1813 & \\
\hline-4 & 0.0005 & 0.4482 & 0.6045 & 0.0005 & 0.5373 & 0.8023 & 0.1407 & 2.2929 & $*$ & 2.0373 & $*$ \\
\hline-3 & -0.0002 & -0.1798 & -0.4250 & 0.0004 & 0.4561 & 1.0647 & 0.1531 & 2.4962 & $*$ & 2.2648 & $*$ \\
\hline-2 & -0.0010 & -0.8971 & -1.5132 & -0.0006 & -0.6203 & -0.0397 & 0.0611 & 0.9957 & & 0.7682 & \\
\hline-1 & -0.0001 & -0.1209 & -1.1395 & 0.0005 & 0.5552 & -0.0915 & 0.0695 & 1.1322 & & 0.9837 & \\
\hline 0 & -0.0013 & -1.2234 & -1.8833 & 0.0001 & 0.0803 & 0.5796 & 0.1127 & 1.8368 & & 1.9794 & $*$ \\
\hline 1 & 0.0011 & 1.0609 & 0.5899 & -0.0006 & -0.6308 & -0.0092 & 0.0726 & 1.1838 & & 1.5664 & \\
\hline 2 & 0.0018 & 1.6634 & 1.8576 & -0.0009 & -0.9489 & -0.7077 & 0.1067 & 1.7388 & & 1.4586 & \\
\hline 3 & 0.0015 & 1.3733 & 0.8390 & -0.0007 & -0.7440 & -1.0403 & 0.0517 & 0.8423 & & 0.8540 & \\
\hline 4 & -0.0006 & -0.5432 & -0.9270 & -0.0009 & -1.0271 & -1.0250 & 0.0094 & 0.1533 & & 0.3153 & \\
\hline 5 & 0.0016 & 1.4933 & 1.3666 & 0.0001 & 0.0697 & -0.5796 & 0.0283 & 0.4611 & & 0.3392 & \\
\hline$[-5,0]$ & -0.0049 & -1.8640 & $-2.4202 *$ & 0.0024 & 1.0398 & 1.1184 & 0.6439 & 4.2854 & $* *$ & 3.7619 & $* *$ \\
\hline$[-1,0]$ & -0.0014 & -0.9506 & $-2.1374 *$ & 0.0006 & 0.4494 & 0.3451 & 0.1821 & 2.0994 & $*$ & 2.0953 & $*$ \\
\hline$[0,1]$ & -0.0002 & -0.1149 & -0.9145 & -0.0005 & -0.3892 & 0.4034 & 0.1853 & 2.1359 & $*$ & 2.5072 & $*$ \\
\hline$[0,5]$ & 0.0041 & 1.5613 & 0.7524 & -0.0030 & -1.3067 & -1.1358 & 0.3813 & 2.5377 & $*$ & 2.6589 & $* *$ \\
\hline
\end{tabular}


Table 6 This table summarizes daily average abnormal returns, absolute value abnormal returns, and abnormal trading volumes around annual general meeting dates in Germany. It also shows cumulative results at the bottom. Superscript $* * *$ and $* *$ indicate significance at $1 \%$ and $5 \%$ levels, respectively.

\begin{tabular}{|c|c|c|c|c|c|c|c|c|c|c|c|c|c|c|c|}
\hline \multirow[b]{2}{*}{ Day } & \multicolumn{5}{|c|}{ Panel 1} & \multicolumn{5}{|c|}{ Panel 2} & \multicolumn{5}{|c|}{ Panel 3} \\
\hline & AAR & t-stat & & Corrado & & AAAR & t-stat & & Corrado & & AAV & t-stat & & Corrado & \\
\hline-5 & -0.0005 & -0.3503 & & -0.2976 & & 0.0008 & 0.5878 & & 0.7326 & & 0.1637 & 2.6705 & $* *$ & 2.1687 & $*$ \\
\hline-4 & 0.0007 & 0.4646 & & 0.4118 & & 0.0001 & 0.0721 & & 0.4901 & & 0.1904 & 3.1075 & $* *$ & 2.3007 & $*$ \\
\hline-3 & 0.0031 & 2.2010 & $*$ & 2.0319 & $*$ & 0.0000 & -0.0290 & & 0.0053 & & 0.0657 & 1.0714 & & 1.1341 & \\
\hline-2 & 0.0007 & 0.4795 & & 0.6853 & & 0.0031 & 2.2704 & $*$ & 1.0620 & & 0.2144 & 3.4981 & $* *$ & 2.1211 & $*$ \\
\hline-1 & 0.0003 & 0.1953 & & 0.4929 & & -0.0006 & -0.4239 & & -0.1133 & & 0.5782 & 9.4345 & $* *$ & 4.1102 & $* *$ \\
\hline 0 & 0.0048 & 3.4389 & $* *$ & 2.3325 & $*$ & 0.0034 & 2.5163 & $*$ & 2.1529 & $*$ & 1.1950 & 19.4978 & $* *$ & 4.4522 & $* *$ \\
\hline 1 & -0.0224 & -15.9983 & $* *$ & -6.7660 & $* *$ & 0.0162 & 11.9618 & $* *$ & 5.9660 & $* *$ & 0.4048 & 6.6049 & $* *$ & 3.7985 & $* *$ \\
\hline 2 & -0.0013 & -0.9423 & & -0.9228 & & -0.0010 & -0.7351 & & -0.0949 & & 0.0701 & 1.1432 & & 0.9632 & \\
\hline 3 & 0.0000 & 0.0161 & & -0.1052 & & -0.0010 & -0.7735 & & -0.9961 & & 0.0872 & 1.4224 & & 1.0627 & \\
\hline 4 & -0.0015 & -1.0933 & & -1.3376 & & -0.0008 & -0.6096 & & -0.1766 & & 0.1135 & 1.8521 & & 1.5497 & \\
\hline 5 & -0.0019 & -1.3507 & & -0.8476 & & -0.0008 & -0.5654 & & -0.8301 & & 0.0560 & 0.9140 & & 0.7813 & \\
\hline$-5,0$ & 0.0090 & 2.6247 & $* *$ & 2.3094 & $*$ & 0.0068 & 2.0387 & $*$ & 1.7675 & & 2.4074 & 16.0359 & $* *$ & 6.6492 & $* *$ \\
\hline$-1,0$ & 0.0051 & 2.5698 & $*$ & 1.9979 & $*$ & 0.0028 & 1.4796 & & 0.9734 & & 1.7732 & 20.4582 & $* *$ & 6.0545 & $* *$ \\
\hline 0,1 & -0.0176 & -8.8808 & $* *$ & -3.1350 & $* *$ & 0.0196 & 10.2375 & $* *$ & 5.7409 & $* *$ & 1.5998 & 18.4574 & $* *$ & 5.8341 & $* *$ \\
\hline 0,5 & -0.0223 & -6.5032 & $* *$ & -3.1217 & $* *$ & 0.0159 & 4.8151 & $* *$ & 2.4582 & $* *$ & 1.9265 & 12.8331 & $* *$ & 5.1470 & $* *$ \\
\hline
\end{tabular}


Table 7 This table summarizes daily average abnormal returns, absolute value abnormal returns, and abnormal trading volumes around annual general meeting dates in Japan. It also shows cumulative results at the bottom. Superscript $* * *$ and $* *$ indicate significance at $1 \%$ and $5 \%$ levels, respectively.

\begin{tabular}{|c|c|c|c|c|c|c|c|c|}
\hline & \multicolumn{2}{|c|}{ Panel 1} & \multicolumn{3}{|c|}{ Panel 2} & \multicolumn{3}{|c|}{ Panel 3} \\
\hline Day & AAR & Corrado & AAAR & Corrado & & AAV & Corrado & \\
\hline-5 & -0.0008 & -0.5323 & -0.0026 & -1.5337 & & -0.1134 & -1.0372 & \\
\hline-4 & -0.0011 & -0.8295 & -0.0025 & -1.2487 & & -0.1049 & -1.2943 & \\
\hline-3 & -0.0014 & -1.2028 & -0.0032 & -1.8544 & & -0.1796 & -1.9055 & \\
\hline-2 & -0.0006 & -0.3353 & -0.0026 & -1.5919 & & -0.1513 & -1.5837 & \\
\hline-1 & 0.0000 & 0.1106 & -0.0020 & -1.0350 & & -0.1240 & -1.2826 & \\
\hline 0 & 0.0003 & 0.3007 & -0.0031 & -1.7156 & & -0.1441 & -1.5441 & \\
\hline 1 & -0.0008 & -0.5910 & -0.0038 & -2.1094 & $*$ & -0.1105 & -1.0269 & \\
\hline 2 & -0.0016 & -1.5208 & -0.0031 & -1.7981 & & -0.1455 & -1.6087 & \\
\hline 3 & 0.0003 & 0.3353 & -0.0038 & -2.2594 & $*$ & -0.1721 & -1.8349 & \\
\hline 4 & 0.0000 & -0.1313 & -0.0022 & -1.1325 & & -0.1531 & -1.5984 & \\
\hline 5 & 0.0011 & 1.2443 & -0.0035 & -2.2575 & $*$ & -0.1532 & -1.5117 & \\
\hline$-5,0$ & -0.0034 & -1.0160 & -0.0159 & -3.6658 & $* *$ & -0.8174 & -3.5303 & $* *$ \\
\hline$-1,0$ & 0.0004 & 0.2908 & -0.0050 & -1.9450 & & -0.2681 & -1.9987 & $*$ \\
\hline 0,1 & -0.0005 & -0.2053 & -0.0068 & -2.7047 & $* *$ & -0.2546 & -1.8180 & \\
\hline 0,5 & -0.0006 & -0.1482 & -0.0195 & -4.6020 & $* *$ & -0.8786 & -3.7252 & $* *$ \\
\hline
\end{tabular}


Table 8 This table summarizes daily average abnormal returns, absolute value abnormal returns, and abnormal trading volumes around annual general meeting dates in France. It also shows cumulative results at the bottom. Superscript $* * *$ and $* *$ indicate significance at $1 \%$ and $5 \%$ levels, respectively.

\begin{tabular}{|c|c|c|c|c|c|c|c|c|c|c|c|c|c|c|c|}
\hline & \multicolumn{5}{|c|}{ Panel 1} & \multicolumn{5}{|c|}{ Panel 2} & \multicolumn{5}{|c|}{ Panel 3} \\
\hline Day & AAR & t-stat & & Corrado & & AAAR & t-stat & & Corrado & & AAV & t-stat & & Corrado & \\
\hline-5 & 0.0022 & 1.4668 & & 0.6694 & & 0.0003 & 0.3069 & & -0.1812 & & 0.0968 & 1.7142 & & 1.4190 & \\
\hline-4 & -0.0007 & -0.4645 & & -1.3877 & & 0.0012 & 1.0608 & & 0.1032 & & 0.0813 & 1.4393 & & 0.1558 & \\
\hline-3 & -0.0003 & -0.2062 & & 0.2340 & & -0.0007 & -0.6058 & & -0.4531 & & 0.0298 & 0.5284 & & -0.1390 & \\
\hline-2 & 0.0023 & 1.5452 & & 0.8816 & & -0.0006 & -0.5580 & & -0.7224 & & 0.0718 & 1.2726 & & 0.4458 & \\
\hline-1 & -0.0009 & -0.6001 & & -0.0980 & & -0.0012 & -1.0931 & & -1.1578 & & 0.1594 & 2.8229 & $* *$ & 1.9176 & \\
\hline 0 & 0.0008 & 0.5100 & & 0.2694 & & 0.0013 & 1.1819 & & 1.2912 & & 0.3108 & 5.5058 & $* *$ & 3.6745 & $* *$ \\
\hline 1 & 0.0010 & 0.6718 & & 0.5633 & & 0.0001 & 0.0559 & & 0.2492 & & 0.2179 & 3.8600 & $* *$ & 2.6582 & $* *$ \\
\hline 2 & -0.0036 & -2.4393 & $*$ & -2.0299 & $*$ & 0.0030 & 2.7680 & $* *$ & 2.2577 & $*$ & 0.1166 & 2.0662 & $*$ & 1.4262 & \\
\hline 3 & -0.0009 & -0.5926 & & -0.6068 & & -0.0007 & -0.6545 & & -0.2341 & & 0.2422 & 4.2902 & $* *$ & 1.5221 & \\
\hline 4 & -0.0046 & -3.1112 & $* *$ & -3.0367 & $* *$ & 0.0012 & 1.0966 & & 0.7123 & & 0.1477 & 2.6169 & $* *$ & 2.2579 & $* *$ \\
\hline 5 & -0.0052 & -3.4851 & $* *$ & -3.5074 & $* *$ & 0.0028 & 2.5540 & $*$ & 2.5069 & $*$ & 0.1681 & 2.9774 & $* *$ & 2.5312 & $* *$ \\
\hline$[-5,0]$ & 0.0033 & 0.9190 & & 0.2322 & & 0.0003 & 0.1195 & & -0.4573 & & 0.7499 & 5.4228 & $* *$ & 3.0511 & $* *$ \\
\hline$[-1,0]$ & -0.0001 & -0.0637 & & 0.1212 & & 0.0001 & 0.0628 & & 0.0943 & & 0.4702 & 5.8893 & $* *$ & 3.9542 & $* *$ \\
\hline$[0,1]$ & 0.0017 & 0.8357 & & 0.5888 & & 0.0014 & 0.8753 & & 1.0892 & & 0.5287 & 6.6227 & $* *$ & 4.4779 & $* *$ \\
\hline$[0,5]$ & -0.0125 & -3.4482 & $* *$ & -3.4081 & $* *$ & 0.0077 & 2.8586 & $* *$ & 2.7693 & $* *$ & 1.2034 & 8.7025 & $* *$ & 5.7441 & $* *$ \\
\hline
\end{tabular}


Table 9 This table summarizes daily average abnormal returns, absolute value abnormal returns, and abnormal trading volumes around annual general meeting dates in Spain. It also shows cumulative results at the bottom. Superscript $* * *$ and $* *$ indicate significance at $1 \%$ and $5 \%$ levels, respectively.

\begin{tabular}{|c|c|c|c|c|c|c|c|c|c|c|c|c|c|}
\hline \multirow[b]{2}{*}{ Day } & \multicolumn{4}{|c|}{ Panel 1} & \multicolumn{4}{|c|}{ Panel 2} & \multicolumn{5}{|c|}{ Panel 3} \\
\hline & AAR & t-stat & Corrado & & AAAR & t-stat & & Corrado & AAV & t-stat & & Corrado & \\
\hline-5 & 0.0018 & 1.4494 & 1.7558 & & -0.0009 & -1.0336 & & -0.8670 & 0.0776 & 1.3671 & & 1.1533 & \\
\hline-4 & 0.0005 & 0.4397 & 0.3192 & & 0.0001 & 0.1551 & & 0.9227 & 0.1621 & 2.8571 & $*$ & 1.5918 & \\
\hline-3 & 0.0018 & 1.4723 & 2.0783 & $*$ & -0.0022 & -2.4923 & $*$ & $-2.3433 *$ & 0.0501 & 0.8822 & & 0.6482 & \\
\hline-2 & -0.0001 & -0.0898 & 0.6551 & & 0.0003 & 0.3449 & & 0.3954 & 0.0577 & 1.0172 & & 0.7411 & \\
\hline-1 & 0.0019 & 1.5415 & 2.7301 & $* *$ & 0.0002 & 0.2507 & & 0.2197 & 0.1102 & 1.9416 & & 1.5441 & \\
\hline 0 & 0.0004 & 0.3088 & 0.3558 & & 0.0008 & 0.8529 & & 0.9227 & 0.1257 & 2.2148 & $*$ & 1.3154 & \\
\hline 1 & 0.0006 & 0.4460 & 0.0964 & & -0.0005 & -0.5784 & & -0.7821 & 0.0716 & 1.2617 & & 0.3527 & \\
\hline 2 & 0.0005 & 0.4034 & 0.1663 & & 0.0006 & 0.6457 & & 0.4042 & 0.1681 & 2.9624 & $* *$ & 2.1613 & $*$ \\
\hline 3 & -0.0016 & -1.3105 & -1.6693 & & 0.0001 & 0.1565 & & 0.4569 & 0.1026 & 1.8079 & & 1.6133 & \\
\hline 4 & 0.0007 & 0.5897 & 0.3226 & & 0.0002 & 0.6606 & & 0.9315 & 0.0891 & 1.5703 & & 1.3368 & \\
\hline 5 & -0.0008 & -0.6408 & -0.0499 & & 0.0008 & 0.5157 & & 0.1845 & 0.1179 & 2.0781 & * & 2.3186 & $*$ \\
\hline$[-5,0]$ & 0.0064 & 2.0910 & 3.2229 & $* *$ & -0.0017 & -0.7848 & & -0.3061 & 0.5832 & 4.1968 & $* *$ & 2.8553 & $* *$ \\
\hline$[-1,0]$ & 0.0023 & 1.0955 & 2.1821 & $*$ & 0.0010 & 0.7804 & & 0.8078 & 0.2358 & 2.9391 & $* *$ & 2.0220 & $*$ \\
\hline$[0,1]$ & 0.0009 & 0.4469 & 0.3198 & & 0.0002 & 0.1941 & & 0.0994 & 0.1972 & 2.4583 & $*$ & 1.1795 & \\
\hline$[0,5]$ & -0.0003 & -0.0695 & -0.3177 & & 0.0020 & 0.9198 & & 0.8646 & 0.6749 & 4.8562 & $* *$ & 3.7143 & $* *$ \\
\hline
\end{tabular}


Table 10 Price and trading volume response the day of the AGM.

\begin{tabular}{|l|c|c|c|c|c|c|}
\hline \multicolumn{1}{|c|}{ AGM day } & U.K. & U.S. & Germany & Japan & France & Spain \\
\hline Returns & No response & No response & + & $\begin{array}{c}\text { No } \\
\text { response }\end{array}$ & No response & No response \\
\hline Returns volatility & No response & No response & + & $\begin{array}{c}\text { No } \\
\text { response }\end{array}$ & No response & No response \\
\hline Trading Volume & + & + & + & $\begin{array}{c}\text { No } \\
\text { response }\end{array}$ & + & No response \\
\hline
\end{tabular}

